\title{
The clinical and public health problem of relapse despite primaquine therapy: case review of repeated relapses of Plasmodium vivax acquired in Papua New Guinea
}

\author{
R Joan H Ingram¹, Chelzie Crenna-Darusallam², Saraswati Soebianto ${ }^{3}$, Rintis Noviyanti ${ }^{4}$ and J Kevin Baird ${ }^{3,4^{*}}$
}

\begin{abstract}
Background: Primaquine is the only drug available for preventing relapse following a primary attack by Plasmodium vivax malaria. This drug imposes several important problems: daily dosing over two weeks; toxicity in patients with glucose-6-phosphate dehydrogenase (G6PD) deficiency; partner blood schizontocides possibly impacting primaquine safety and efficacy; cytochrome P-450 abnormalities impairing metabolism and therapeutic activity; and some strains of parasite may be tolerant or resistant to primaquine. There are many possible causes of repeated relapses in a patient treated with primaquine.
\end{abstract}

Case description: A 56-year-old Caucasian woman from New Zealand traveled to New Ireland, Papua New Guinea for two months in 2012. One month after returning home she stopped daily doxycycline prophylaxis against malaria, and one week later she became acutely ill and hospitalized with a diagnosis of Plasmodium vivax malaria. Over the ensuing year she suffered four more attacks of vivax malaria at approximately two-months intervals despite consuming primaquine daily for 14 days after each of those attacks, except the last. Genotype of the patient's cytochrome P-450 2 D6 alleles $(* 5 / 41)$ corresponded with an intermediate metabolizer phenotype of predicted low activity.

Discussion: Multiple relapses in patients taking primaquine as prescribed present a serious clinical problem, and understanding the basis of repeated therapeutic failure is a challenging technical problem. This case highlights these issues in a single traveler, but these problems will also arise as endemic nations approach elimination of malaria transmission.

Keywords: Plasmodium vivax, Relapse, Primaquine, Resistance, Tolerance, Compliance, Therapeutic failure, CYP2D6 polymorphism

\section{Background}

Endemic Plasmodium vivax puts 2.7 billion residents at risk of infection, and very many visitors [1]. In the USA, during 1990 to 2010, between 400 and 700 Americans were diagnosed with vivax malaria each year [2]. In the UK, between 2002 and 2005, a total of 1,244 cases of $P$. vivax malaria were reported [3]. Each primary attack carries risk of repeated attacks called relapses in the weeks and months to follow, for up to three years [4].

\footnotetext{
* Correspondence: kbaird@eocru.org

${ }^{3}$ Eijkman-Oxford Clinical Research Unit, Jakarta 10430, Indonesia

${ }^{4}$ Centre for Tropical Medicine, Nuffield Department of Medicine, University of Oxford, Oxford, UK

Full list of author information is available at the end of the article
}

The probability, number, and timing of relapses vary by geographic origin of the strain [5]. Three to five relapses may be considered typical, and up to 20 within two years have been documented [6].

Despite long being considered relatively benign and very rarely fatal, recent work demonstrates the potential for serious morbidity and even mortality with vivax malaria [2,7-11]. Severe anaemia is the most common threatening syndrome, followed by acute respiratory distress, kidney failure, severe thrombocytopaenia, coma, and shock syndromes. Severe and fatal complications in travellers also occur $[7,12]$. Preventing repeated attacks 
of relapsing vivax malaria offers the opportunity to avoid threatening illness and onward transmission.

Primaquine alone has proven safety and efficacy against the latent parasite in the liver (hypnozoites) responsible for relapsing vivax malaria. Licensed in 1952, primaquine has been combined with chloroquine against the asexual blood stages to achieve radical cure, i.e., elimination of all forms of the parasite. A wide variety of primaquine regimens have been applied against relapse [13], but today experts agree that $0.5 \mathrm{mg} / \mathrm{kg}$ daily for 14 days should prevent relapse [14].

Primaquine toxicity in glucose-6-phosphate dehydrogenase (G6PD)-deficient patients imposes several important obstacles to achieving radical cure. Adherence to 14 days of daily dosing may be unlikely without firm guidance from the provider and follow up [15]. However, strict adherence invites risk of serious harm in most G6PD-deficient patients. So most providers do not offer primaquine therapy without knowing G6PD status [16]. When providers do offer primaquine, advice to fully adhere must include the caution to cease dosing with signs of haemolysis. A robust point-of-care diagnosis of G6PD deficiency would mitigate this problem of safe access to effective therapy against relapse, but not all of them.

Several other problems diminish effectiveness of radical cure by primaquine. Differential cytochrome P450 2D6 isozyme metabolism of primaquine by dozens of distinct allelic variants introduces highly complex determinants of clinical efficacy. Further, the rise of resistance to primaquine's partner in radical cure, chloroquine, requires adopting other blood schizontocides as therapy, but the safety and efficacy of primaquine against relapse may vary when combined with those partner drugs in radical cure [17]. Each new partner therapy requires new evidence of primaquine safety and efficacy, and such is relatively difficult to obtain. Pregnant or lactating women, and infants may not receive primaquine therapy [18], and these groups are the most vulnerable to severe and threatening vivax malaria in endemic communities [19,20].

Sixty years of continuous primaquine use requires consideration of the potential problem of resistance to it by hypnozoites. However, as the case described in this report illustrates, demonstrating either sensitivity or resistance to primaquine is a very complex, multi-tiered endeavour requiring the ruling out of many possible confounding factors. Repeated acute attacks of vivax malaria despite primaquine therapy poses threats to the health and life of the patient, and puts the care providers in the difficult position of identifying the cause of therapeutic failure in order to address it. These patients also raise public health issues, especially regarding strategies for eliminating malaria transmission.

Here, a summary of a case obtained from medical records and the first author's clinical review of the patient is presented to highlight the issue of multiple relapses of $P$. vivax despite apparently adequate primaquine therapy.

\section{Case presentation}

Travel, attacks and treatment

A 56-year-old woman resident in New Zealand weighing $67 \mathrm{~kg}$ arrived at New Ireland, Papua New Guinea in early September 2012. During that visit she consumed $100 \mathrm{mg}$ doxycycline daily up to the end of travel in late October 2012 and for one month following return to New Zealand. She reported being fully compliant with that chemoprophylaxis. She had previously experienced an episode of confirmed Plasmodium falciparum after travel to Africa and wished to avoid another such attack.

A week later, in November 2012, she sought medical attention after developing headache, malaise, and rigors. A diagnosis of $P$. vivax was made microscopically (Figure 1 ). She spent two days in hospital and was discharged after responding to therapy with atovaquone/proguanil $\left(\right.$ Malarone $^{\mathrm{rx}}, 4$ tablets/day $\times 3 \mathrm{~d}$ ). She was prescribed an unknown dose of daily primaquine $\left(\right.$ Primacin $^{\mathrm{Tn}}, \mathrm{BNM}^{\circ}$, Australia) for this first attack after her G6PD test was normal.

Two months later, in January 2013 she suffered a second attack, again confirmed with a microscopic diagnosis and with admission to hospital. She was treated with artemether/lumefantrine (Riamet ${ }^{\mathrm{Tw}}$, 4 tablets twice daily for 3 days) and $30 \mathrm{mg}$ primaquine base daily for 14 days.

Two months later, in March 2013, she suffered a third confirmed attack of $P$. vivax malaria and was hospitalized for several days. She received the same therapy as that prescribed after the second attack. The patient described being fully compliant to daily primaquine therapy with prior treatments. The importance of doing so was again emphasized to the patient.

A fourth attack occurred two months later in May 2013. She was admitted to hospital with a peripheral parasitaemia of asexual $P$. vivax trophozoites infecting $3-4 \%$ of her red blood cells. She was treated with the same regimen of therapy as after the second and third attacks, but with $45 \mathrm{mg}$ primaquine daily for 14 days, rather than $30 \mathrm{mg}$. She spent one day in hospital.

The fifth attack again occurred two months later, in July 2013. She was not admitted to hospital and consumed artemether/lumefantrine as before. Primaquine therapy was judged unlikely to provide any benefit and was not prescribed.

In August 2013 the patient travelled to the Solomon Islands and remained for two months, all the while consuming a commercial dietary supplement containing Artemisia annua herbal extract (equivalent of $17 \mathrm{mg}$ artemisinin daily) that had been recommended to her by a colleague for malaria prevention. She remained healthy 


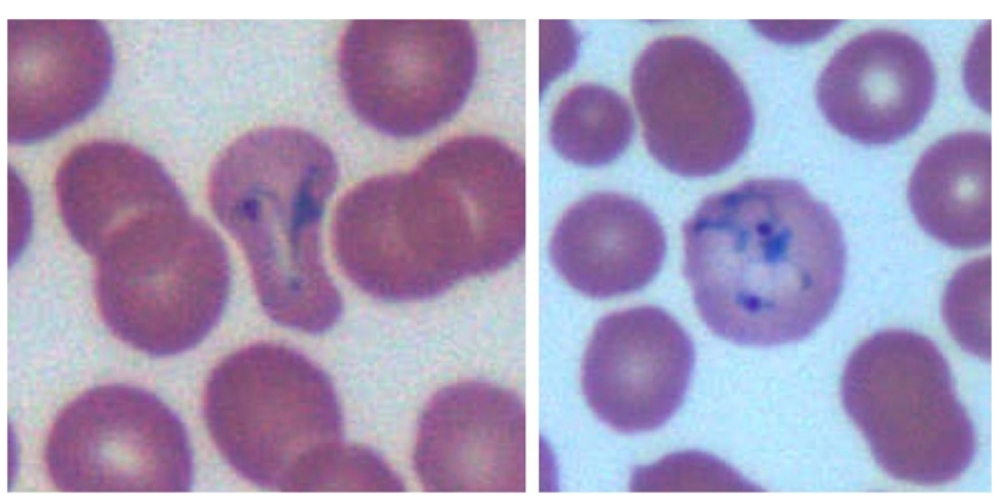

Figure 1 Photomicrograph of an oil-immersion microscopic examination of a Giemsa-stained thin blood smear taken from the patient illustrating amoeboid trophozoites within enlarged and mutable infected red blood cells consistent with a diagnosis of infection by Plasmodium vivax.

while abroad. Five months after returning to New Zealand, she again suffered an attack of vivax malaria (March 2014). This was treated initially and partially with chloroquine (two doses) with a switch to atovaquone/proguanil, and primaquine was again not prescribed for the same reasons as in July 2013.

The patient travelled to Vanuatu for two weeks in April and May 2014, taking 100 mg doxycycline daily while there, and continues that regimen up to December 2014 with intervening travel to the Solomon Islands. As of December 2014 she has not suffered any attacks of malaria since March 2014, but has on three occasions developed severe headache, weakness and chills which have settled within 24 hours without medical attention.

Although these six episodes of vivax malaria were not complicated, each caused marked symptoms and most led to admission to hospital. These events were debilitating and disruptive of the patient's routines, and she firmly declared that she took the four courses of primaquine precisely as directed.

\section{Plasmodium diagnostics}

Giemsa-stained thin blood films were taken at each presentation with acute illness. Demonstration of amoeboid trophozoites within enlarged infected red blood cells provided the diagnosis of vivax malaria (Figure 1) at the laboratory. Expert malaria microscopists at the EijkmanOxford Clinical Research Unit in Jakarta, Indonesia affirmed that diagnosis. At the molecular diagnostic referral laboratory also in Jakarta (Eijkman Institute for Molecular Biology), a vial of extracted DNA from blood taken at the final attack of malaria was analyzed by nested PCR of ssrRNA using standardized methodology employing genus and species-specific primers (for Plasmodium malariae, Plasmodium ovale, $P$. falciparum, and $P$. vivax) [21]. These were strongly positive for $P$. vivax and negative for the other species.

\section{CYP2D6 genotyping}

Isolated DNA was collected from the patient and extracted using Puregen $\mathrm{e}^{\mathrm{Tm}}\left(\right.$ Gentra $\left.^{\circ}\right)$ and its concentration measured at $635 \mathrm{ng} / \mu \mathrm{L}$ (NanoDrop2000 ${ }^{\mathrm{mi}}$, Thermoscientific ${ }^{\circ}$ ) and 1.58 DNA purity (A260/A280). CYP2D6 genotyping was performed using xTAG $^{\mathrm{mm}}$ CYP2D6 kit v3 (Luminex ${ }^{\circ}$ Corporation, USA). Allelic variation categories assayed by this kit included DNA sequences encoding normal function ("1, "2, and "35), reduced function ("9, "10, "17, "29, and "41), and non-functional (*3, "4, "5 -for whole-gene deletion, "6, *7, *8, "11, and "15), including DUP for duplication. The manufacturer's instructions were followed for genotyping by this kit. Amplification and incubation was performed using 9700 thermal cycler (PE Applied Biosystems $\left.{ }^{\circ}\right)$. The Luminex 200 xMAP $^{\mathrm{m}}$ instrument was used to read the fluorescence absorbance from a specific probe that hybridized with the beads. The data were then analysed automatically using the xTAG Data Analysis Software $^{\text {Tx }}$ to record the CYP2D6 allelic variant.

A CYP2D6 gene deletion (*5) and polymorphisms at $1661 \mathrm{G}>\mathrm{C}, 2850 \mathrm{C}>\mathrm{T}, 2988 \mathrm{G}>\mathrm{A}$, and $4180 \mathrm{G}>\mathrm{C}(* 41)$ were detected. The genotype of the patient was classified as a " $5 / " 41$ allelic variant. According to the prediction of enzymatic activity, the $" 5$ and " 41 allelic variants are categorized as null and dysfunctional, respectively $[22,23]$. The combination of those allelic variants infers an intermediate metabolizer phenotype (Figure 2). Nonetheless, "41 allele is frequently associated with relatively very low enzymatic activity scores when expressed with the null *5, i.e., 0.5 on a scale of 0 to 3 , where 3 is the ultrametabolizer, and 1.5 to 2.0 represent wild type * $1 /{ }^{*} 1$ scores [24]. Absent direct characterization of CYP2D6 metabolizer phenotype - as may be done with a dextromethorphan challenge and pharmacokinetic analysis [25] - it can only be considered it likely that the CYP2D6 genotype in this patient resulted in levels of metabolized primaquine inadequate to the task of killing hypnozoites 


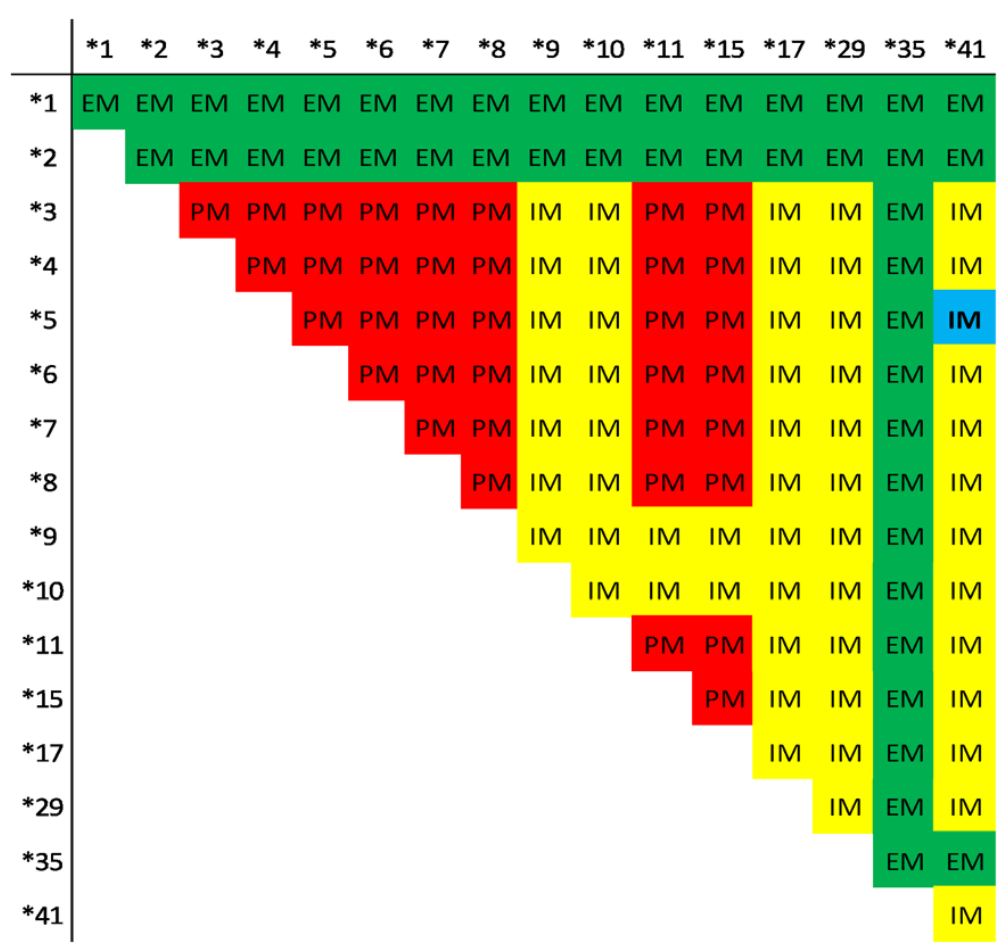

Figure 2 Phenotype prediction from CYP2D6 allelic variants detected by the XTAG $^{\text {TM }}$ CYP2D6 Kit v3 (Luminex ${ }^{\circledR}$ Corp., USA). Green corresponds to extensive metabolizer (EM), yellow to intermediate metabolizer (IM), and red to poor metabolizer phenotypes. Our patient's genotype placement at ${ }^{*} /{ }^{*} 41$ is shown as blue in an intermediate metabolizer phenotype.

of $P$. vivax. Likewise, one research subject experimentally challenged with $P$. vivax and relapsing despite directly observed high-dose primaquine therapy had " $4 / * 41$ genotype of CYP2D6 [26], where "4 has no functional enzyme activity (like the $* 5$ deletion) [23].

\section{Interpretation}

This patient suffered an attack of Plasmodium vivax post-travel, followed by four relapses, each at two-month intervals, and a fifth attack more than six months after the prior attack and intervening travel to another malaria endemic area. She consumed full courses of primaquine after the first, second, third, and fourth attacks, including a round of $45 \mathrm{mg} /$ day for 14 days. None of these prevented her from relapsing at intervals typical of $P$. vivax from that region [5]. The challenge for her care providers, and malariologists weighing strategies for elimination of this parasite, is to understand what failed in this case and what may be done to avoid such poor therapeutic outcomes in the future.

The Plasmodium vivax strain called Chesson came from an American soldier infected in 1944 during the New Guinea campaign of the Pacific War [27]. This strain and most from the Pacific region relapse quickly (usually within a month of onset of the primary attack) and at approximately two-month intervals [28]. Chesson P. vivax also tolerated 14-day courses of primaquine at
$0.25 \mathrm{mg} / \mathrm{kg}$ daily, necessitating $0.5 \mathrm{mg} / \mathrm{kg}$ daily for good efficacy [29]. The parasite infecting the patient described here also came from the New Guinea region and appears Chesson-like in its relapsing behaviour, and proved unresponsive to even $0.75 \mathrm{mg} / \mathrm{kg}$ daily primaquine therapy for 14 days. Understanding why primaquine failed in this patient requires considering many possible explanations, including failure to take therapy as directed, inappropriate partner blood schizontocide, counterfeit or substandard primaquine, re-infection, or polymorphisms in the sole human cytochrome P-450 isozyme (2D6, or CYP2D6) [30] known to metabolize primaquine [31], an essential step in killing hypnozoites [32].

Bennett and colleagues [26] challenged 25 human subjects with $P$. vivax sporozoites, and all suffered a primary attack and were treated with directly observed standard chloroquine and primaquine $(0.5 \mathrm{mg} / \mathrm{kg} / \mathrm{d} \times 14 \mathrm{~d})$ radical cure. Two subjects nonetheless relapsed. The CYP2D6 genotypes of those two subjects were classified as associated with intermediate or poor metabolizers, respectively. The intermediate metabolizer relapsed twice, and the poor metabolizer relapsed three times. Among the 23 subjects who did not relapse, only two were classified as intermediate metabolizers, and the remaining 21 subjects were extensive metabolizers. Higher levels of unmetabolized primaquine in plasma among the defective metabolizers suggested far lower rates of conversion to 
active metabolites. These findings tended to rule out parasite resistance to primaquine as the explanation of the therapeutic failures. Taken with the facts of directly observed therapy and no possible re-infection, those studies pointed to CYP2D6 polymorphisms as being important determinants of efficacy against relapse.

Likewise, a specific CYP2D6 genotype in this patient $(* 5 / * 41)$ seems to account for the poor outcomes of her repeated rounds of primaquine therapy. The parasite infecting the patient relapsed at its naturally short intervals (two months), seemingly unaffected by the primaquine being consumed. Primaquine exerts a cumulative dose effect on hypnozoites called the total dose effect, where the total dose determines efficacy rather than the schedule of delivery [33]. In other words, the same total dose may be delivered as single dose, as 7 or 14 daily doses, or as weekly doses for eight weeks and achieve the same good efficacy [34]. Whereas a total dose of $420 \mathrm{mg}$ is considered efficacious against even the primaquine-tolerant Chesson strain of $P$. vivax, this patient received a total dose of $1,890 \mathrm{mg}$ over an eight-month period, relapsing repeatedly in that interval. Even this very large cumulative total dose appeared inadequate against relapse.

Another possible explanation for therapeutic failure is the role of unproven partner blood schizontocides given to this patient. Her care providers prescribed atovaquoneproguanil and, later, artemether-lumefantrine. Resistance to chloroquine by $P$. vivax in the Asia-Pacific region is widely known [35]. The safety and efficacy of primaquine against relapse depends on the partner blood schizontocide [17]. No clinical trials have proven primaquine safe and effective when used with either of those blood schizontocidal therapies as partner in radical cure. Drug-drug interactions between those therapies somehow disabling therapeutic efficacy against relapse cannot be ruled out in this patient. Poor adherence or faulty primaquine cannot be ruled out, but are considered very unlikely. The patient's CYP2D6 polymorphism was considered the most likely basis of her experiences with $P$. vivax.

\section{Implications}

Primaquine has been the sole therapy against relapse of vivax malaria since 1952 . The parasite has certainly been exposed to sub-therapeutic levels over that period [13]. Acquired resistance to primaquine must be regarded as a possibility, even though hypnozoite resistance to primaquine has yet to be demonstrated in animal models, patients, or study subjects. This may be a product of resistance being absent, or of the difficulty of ruling out all other possible causes of therapeutic failure.

No standardized in vivo protocol has been developed, optimized or validated for the diagnosis of resistance to primaquine in a patient. Re-infection would seriously confound the assessment of primaquine sensitivity, and no molecular diagnostics today differentiate relapse from reinfection. Randomized clinical trials can measure the force of infection of blood via hypnozoites versus sporozoites in populations [36], but such trials are extremely laborious and expensive, and not practical for routine surveillance. All of these difficulties explain why we cannot now conduct surveillance for primaquine resistance/ efficacy in endemic areas. Thus, primaquine efficacy in most settings cannot be known. An analysis of 87 primaquine therapeutic trials since 1950 by John et al. [37] illustrates an attempt at doing so despite the limitations and confounders involved.

Only under relatively rare circumstances - as in experimental challenge or in mobile populations from nonendemic areas being briefly heavily exposed and then repatriated - can the efficacy of primaquine be measured with little or no ambiguity. In one such instance, the efficacy of primaquine against hypnozoites acquired in Indonesian New Guinea was a remarkable $98 \%$ at $0.5 \mathrm{mg} /$ $\mathrm{kg} /$ day X 14d following dihydroartemisinin-piperaquine as partner blood schizontocide [38]. That one study offers hope of good efficacy elsewhere, but does not substitute for a responsibly thorough and effective means of surveillance for resistance to primaquine.

Travellers returning home and suffering vivax malaria may be the sole means now available to reliably estimate the efficacy of primaquine against relapse in any given area. The technical difficulty of interpreting outcomes in this patient in New Zealand illustrates the complexity in understanding the broader determinants of therapeutic efficacy against relapse. The extraordinary diversity and complexity of CYP2D6 polymorphisms will require a great deal more attention in the context of malaria control and elimination. The current case illustrates the value of CYP2D6 assessment in patients needing primaquine therapy.

\section{Conclusions}

The findings in this case review are compatible with therapeutic failure of primaquine as a consequence of a polymorphism of CYP2D6 $\left({ }^{*} 5 / * 41\right)$ impairing metabolism to an active form. Unproven combinations of ACT therapies with primaquine for radical cure exacerbating therapeutic inadequacy may not be ruled out, along with other factors like adherence and sub-standard drug. Defining the determinants of primaquine therapeutic failure against relapse clarifies strategy aimed at achieving maximal effectiveness of primaquine against the hypnozoite reservoir of $P$. vivax. Elimination of vivax malaria may hinge upon success at doing so.

\section{Consent}

Written informed consent was obtained from the patient for publication of this case study and accompanying 
images. A copy of the written consent is available for review by the Editor-in-Chief of this journal.

\section{Abbreviations}

ACT: Artemisinin combined therapy; ASPE: Allele-specific primer extension; CYP: Cytochrome P-450; G6PD: Glucose-6-phosphate dehydrogenase.

\section{Competing interests}

The authors declare that they have no competing interests.

\section{Authors' contributions}

RJHI managed the patient and documented that clinical experience for this report. CD performed the CYP2D6 genotyping, SS managed confirmatory parasite diagnostics, RN supervised the CYP2D6 genotyping and parasitologic molecular diagnostics, and JKB organized all records and data into the presentation of facts and analysis in this report. All authors read and approved the final manuscript.

\section{Acknowledgements}

Haematologists Dr. George Chan at Auckland City Hospital, Auckland, along with Dr. David Wei at Northland District Health Board, Whangarei, each contributed materials to this case investigation. Dr. Decy Subekti and Ms. Lenny Ekawati in Jakarta also contributed to management of specimens. JKB is supported by Wellcome Trust grant B9RJIXO.

\section{Author details}

${ }^{1}$ Auckland City Hospital, Auckland, New Zealand. ${ }^{2}$ Eijkman Institute for Molecular Biology, Jakarta, Indonesia. ${ }^{3}$ Eijkman-Oxford Clinical Research Unit, Jakarta 10430, Indonesia. ${ }^{4}$ Centre for Tropical Medicine, Nuffield Department of Medicine, University of Oxford, Oxford, UK.

\section{Received: 29 September 2014 Accepted: 6 December 2014}

Published: 12 December 2014

\section{References}

1. Gething PW, Elyazar IR, Moyes CL, Smith DL, Battle KE, Guerra CA, Patil AP, Tatem AJ, Howes RE, Myers MF, George DB, Horby P, Wertheim HF, Price RN, Mueller I, Baird JK, Hay SI: A long neglected world malaria map: Plasmodium vivax endemicity in 2010. PLoS Negl Trop Dis 2012, 6:e1814.

2. Hwang J, Cullen KA, Kachur SP, Arguin PM, Baird JK: Severe morbidity and mortality risk from malaria in the United States, 1985-2011. Infect Dis 2014, 1:1.

3. Smith AD, Bradely DJ, Smith V, Blaze M, Behrens RH, Chiodini PL, Whitty C Imported malaria and high risk groups: observational study using UK surveillance data. Brit Med J 2008, 337:a120.

4. White NJ: Determinants of relapse periodicity in Plasmodium vivax malaria. Malar J 2011, 10:297.

5. Battle KE, Karhunen MS, Bhatt S, Gething PW, Howes RE, Golding N, Van Boeckel TP, Messina JP, Shanks GD, Smith DL, Baird JK, Hay SI: Geographical variation in Plasmodium vivax relapse. Malar J 2014, 13:144.

6. Eyles DE, Young MD: Studies on imported malarias. 7. The parasitological pattern of relapsing Plasmodium vivax in military patients. I Nat Malar Soc 1948, 7:23-37.

7. Baird JK: Evidence and implications of mortality associated with acute Plasmodium vivax malaria. Clin Microbiol Rev 2013, 26:36-57.

8. Anstey NM, Douglas NM, Pospoprodjo JR, Price RN: Plasmodium vivax: clinical spectrum, risk factors and pathogenesis. Adv Parasitol 2012, 80:151-201.

9. Manning L, Laman M, Law I, Bona C, Aipit S, Teine D, Warrell J, Rosanas-Urgell A, Lin E, Kiniboro B, Vince J, Hwaiwhanje I, Karunajeewa H, Michon P, Siba P, Mueller I, Davis TM: Features and prognosis of severe malaria caused by Plasmodium falciparum, Plasmodium vivax and mixed Plasmodium species in Papua New Guinean children. PLoS One 2011, 6:e29203.

10. Tjitra E, Anstey NM, Sugiarto P, Warikar N, Kenangalem E, Karyana M, Lampah DA, Price RN: Multi-drug resistant Plasmodium vivax associated with severe and fatal malaria: a prospective study in Papua, Indonesia. PLoS Med 2008, 5:e128.

11. Quispe AM, Pozo E, Guerrero E, Durand S, Baldeviano GC, Edgel KA, Graf PC, Lescano AG: Plasmodium vivax hospitalizations in a monoendemic malaria region: severe vivax malaria? Am J Trop Med Hyg 2014, 91:11-17.
12. Kotwal RS, Wenzel RB, Sterling RA, Porter WD, Jordan NN, Petrucelli BP: An outbreak of malaria in US Army Rangers returning from Afghanistan. JAMA 2005, 293:212-216.

13. Baird JK, Hoffman SL: Primaquine therapy for malaria. Clin Infect Dis 2004, 39:1336-1345.

14. Hill DR, Baird JK, Parise ME, Lewis LS, Ryan ET, Magill AJ: Primaquine: a report from the CDC expert meeting on malaria chemoprophylaxis I. Am J Trop Med Hyg 2006, 75:402-415.

15. Khantikul N, Butraporn P, Kim HS, Leemingsawat S, Tempongko MA, Suwonkerd W: Adherence to antimalarial drug therapy among vivax malaria patients in northern Thailand. J Health Popul Nutr 2009, 27:4-13.

16. Baird JK: Reinventing primaquine for endemic malaria. Expert Opin Emerg Dis 2012, 42:1049-1054.

17. Baird J: Resistance to chloroquine unhinges vivax malaria therapeutics. Antimicrob Agents Chemother 2011, 55:1827-1830.

18. WHO: Guidelines for the Treatment of Malaria. 2nd edition. Geneva: World Health Organization; 2010:194.

19. Rijken MJ, McGready R, Boel E, Poespoprodjo R, Singh N, Syafruddin D, Rogerson S, Nosten F: Malaria in pregnancy in the Asia-Pacific region. Lancet Infect Dis 2012, 12:75-88.

20. Poespoprodjo JR, Fobia W, Kenangalem E, Lampah DA, Warikar N, Seal A McGready R, Sugiarto P, Tjitra E, Anstey NM, Price RN: Adverse pregnancy outcomes in an area where multidrug-resistant Plasmodium vivax and Plasmodium falciparum infections are endemic. Clin Infect Dis 2008, 46:1374-1381.

21. Singh B, Bobogare A, Cox-Singh J, Snounou G, Abdullah MS, Rahman HA: A genus and species specific nested polymerase chain reaction malaria detection assay for epidemiologic studies. Am J Trop Med Hyg 1999, 60:687-692.

22. Zhou SF: Polymorphism of human cytochrome P450 2D6 and its clinical significance. Part 1. Clin Pharmacokinet 2009, 48:689-723.

23. Sistonen J, Fuselli S, Palo JU, Chauhan N, Padh H, Sajantila A: Pharmacogenetic variation at CYP2C9, CYP2C19, and CYP2D6 at gobal and microgeographic scales. Pharmacogen Genom 2009, 19:170-179.

24. Microsomes containing metabolizer phenotype-specific CYP2D6 isozyme. http://www.xenotechllc.com/products/subcellular-fractions/human/liver/ genotyped/cyp2d6.

25. Jurica J, Bartecek R, Zourkova A, Pindurova E, Sulcova A, Kasparek T, Zendulka O: Serum dextromethorphan/dextrorphan metabolic ratio for CYP2D6 phenotyping in clinical practice. J Clin Pharm Ther 2012, 37:486-490.

26. Bennett JW, Pybus BS, Yadava A, Tosh D, Sousa JC, McCarthy WF, Deye G, Melendez V, Ockenhouse CF: Primaquine failure and cytochrome P-450 2D6 in Plasmodium vivax malaria. N Engl J Med 2013, 369:1381-1382.

27. Ehrman FC, Ellis JM, Young MD: Plasmodium vivax Chesson strain. Science 1945, 101:377

28. Young MD, Eyles DE, Burgess RW: Studies on imported malaria. 10. An evaluation of the foreign malarias introduced in the United States by returning troops. J Nat Malar Soc 1948, 7:171-185.

29. Edgecomb JH, Arnold J, Yount EH Jr, Alving AS, Eichelberger L: Primaquine, SN 13272: a new curative agent in vivax malaria. A preliminary report. J Nat Malar Soc 1950, 9:285-292.

30. Zanger UM, Raimundo S, Echelbaum M: Cytochrome P450 2D6: overview and update on pharmacology, genetics, biochemistry. Naunyn Schmiedebergs Arch Pharmacol 2004, 369:23-37.

31. Pybus BS, Marcsisin SR, Jin X, Deye G, Sousa JC, Li Q, Caridha D, Zeng Q, Reichard GA, Ockenhouse C, Bennett J, Walker LA, Ohrt C, Melendez V: The metabolism of primaquine to its active metabolite is dependent on CYP2D6. Malar J 2013, 12:212.

32. Vasquez-Vivar J, Augusto O: Hydroxylated metabolites of the antimalarial drug primaquine. J Biol Chem 1992, 267:6848-6854.

33. Schmidt $L H$, Fradkin R, Vaughan $D$, Rasco J: Radical cure of infections with Plasmodium cynomolgi: a function of total 8-aminoquinoline dose. Am J Trop Med Hyg 1977, 26:1116-1128.

34. Alving AS, Johnson CF, Tarlov AR, Brewer GJ, Kellermeyer RW, Carson PE: Mitigation of the hemolytic effect of primaquine and enhancement of its action against exoerythrocytic forms of the Chesson strain of Plasmodium vivax by intermittent regimens of drug administration. Bull World Health Organ 1960, 22:621-631.

35. Price RN, von Seidlein L, Valecha N, Nosten F, Baird JK, White NJ: Global extent of chloroquine-resistant Plasmodium vivax: a systematic review and meta-analysis. Lancet Infect Dis 2014, 14:982-991. in press. 
36. Baird JK: Resistance to therapies for infection by Plasmodium vivax. Clin Microbiol Rev 2009, 22:508-534.

37. John GK, Douglas NM, von Seidlein L, Nosten F, Baird JK, White NJ, Price RN: Primaquine radical cure of Plasmodium vivax: a critical review of the literature. Malar J 2012, 11:280.

38. Sutanto I, Tjahjono B, Basri H, Taylor WR, Putri FA, Meilia RA, Setiabudy R, Nurleila S, Ekawati LL, Elyazar I, Farrar J, Sudoyo H, Baird JK: Randomized, open-label trial of primaquine against vivax malaria relapse in Indonesia. Antimicrob Agents Chemother 2013, 57:1128-1135.

doi:10.1186/1475-2875-13-488

Cite this article as: Ingram et al: The clinical and public health problem of relapse despite primaquine therapy: case review of repeated relapses of Plasmodium vivax acquired in Papua New Guinea. Malaria Journal 2014 13:488.

\section{Submit your next manuscript to BioMed Central and take full advantage of:}

- Convenient online submission

- Thorough peer review

- No space constraints or color figure charges

- Immediate publication on acceptance

- Inclusion in PubMed, CAS, Scopus and Google Scholar

- Research which is freely available for redistribution 